\title{
SIERRA DE SALINAS: EL FRACASO DE UNA COLONIZACIÓN
}

\author{
Gregorio Canales Martínez
}

Un eslabón más en la labor colonizadora emprendida por el Estado, es la Ley de Colonización y Repoblación interior de 30 de agosto de 1907, que dio origen a 18 grupos coloniales distribuidos por diferentes provincias, y afectó a unas $11.000 \mathrm{Ha}$., de las cuales 5.000 se destinaron a cultivos y las restantes a aprovechamiento forestal de carácter comunal ${ }^{1}$. De esta obra de colonización, una de las provincias más beneficiadas fue Alicante, con casi un cuarto de la superficie total afectada (el 21,2\%) y con el 29,3\% de la cultivada. Esta provincia conoció la creación de tres colonias: Sierra de Salinas en Villena; El Montgó en Denia y Els Plans en Alcoy (vid. cuadro I).

La Colonia Sierra de Salinas es el objeto de análisis de este trabajo por abarcar la mayor superficie colonizable y porque desde un principio representó -al igual que Els Plans- la creación de un nuevo espacio agrícola. No así El Montgó, donde la colonización supuso la replantación de viñedos en terrenos en los que este cultivo se perdió tras la invasión filoxérica de principios de siglo.

\section{1.- LA LEY DE 30 DE AGOSTO DE 1907}

La normativa legal creada para la colonización, reconocía en su articulado el carácter experimental que la ley tenía, de ahí que redujera su alcance a los terrenos y montes declarados enajenables del Ministerio de Hacienda, siempre que fueran susceptibles de transformación agrícola.

Los antecedentes de esta Ley se encuentran en las disposiciones que sobre colonias agrícolas se dictaron en la segunda mitad del siglo XIX, y cuyo expo-

1 ALCARAZ, E., La colonización interior de España, Dirección General de Agricultura, Servicio de Publicaciones Agrícolas, Ministerio de Economía, Madrid, 1931, p. 43. 
nente más representativo fue la Ley de $1868^{2}$. Pese a compartir con aquélla los mismos objetivos en favor de la agricultura, como el incremento y diseminación de la población junto con la extensión y mejora de cultivos, difiere en cuanto al procedimiento empleado: la Ley de 1868 amparaba la iniciativa particular en la colonización agrícola ${ }^{3}$, concediendo exenciones impositivas como aliciente para la roturación, atrayéndose por ello la enemistad de los municipios. Por el contrario en la Ley de 1907 es el Estado quien emprende directamente la colonización de sus tierras facilitando a los colonos los auxilios necesarios para la instalación y explotación de los terrenos adjudicados.

\section{CUADRO I}

Colonias Agrícolas en la Provincia de Alicante: extensión y número de colonos.

\begin{tabular}{|c|c|c|c|c|c|c|}
\hline Colonia & Municipio & Superficie (Ha.) & & $\%$ & $N$ & \\
\hline & & & & & $\underline{\text { Colonos }}$ & $\%$ \\
\hline Els Plans & Alcoy & 311 & 13,34 & 10 & 9,52 & \\
\hline Sierra de Salinas & Villena & 1.363 & 58,47 & 49 & 46,67 & \\
\hline \multirow[t]{2}{*}{ El Montgó } & Denia & 657 & 28,19 & 46 & 43,81 & \\
\hline & & 2.331 & 100 & 105 & 100 & \\
\hline
\end{tabular}

El Estado ejercía la protección tutelar durante los cinco primeros años de desarrollo colonizador, al término de los cuales el colono adquiría la propiedad de la tierra y empezaba a satisfacer la correspondiente contribución territorial. A cambio, se imponían a los beneficiarios condiciones restrictivas, entre las cuales deben señalarse: la extensión del lote; la obligación de instaurar bosque en una parte del mismo; y el sometimiento obligatorio del colono a una Asociación Cooperativa de producción, consumo y asistencia, formada por todos los miembros de cada colonia ${ }^{4}$.

2 Gil Olcina ha puesto de manifiesto el gran alcance que tuvo la Ley de 1868, cuyos establecimientos coloniales salpicaron casi todas las provincias, en un proceso de larga duración al que no fueron ajenos prominentes personajes políticos, como el marqués del Duero y don Ramón de Campoamor promotores respectivos de las colonias San Pedro Mártir en Marbella y Campoamor en Orihuela. GIL OLCINA, A., "Crisis y transferencia de las propiedades estamental y pública», La propiedad rústica en España y su influencia en la organización del espacio, Departamento de Geografía, Universidad de Alicante, 1982, p. 27.

3 El autor del artículo ha estudiado la fuerte repercusión que la normativa de 1868 tuvo en la roturación del secano del Bajo Segura. CANALES MARTÍNEZ, G., «Primer intento de transformación en el secano del Bajo Segura: la Ley de 3 de junio de 1868 sobre colonias agrícolas», en las actas del II Coloquio de Estructuras de la Propiedad de la tierra en España (en prensa).

4 JUNTA CENTRAL DE COLONIZACIÓN Y REPOBLACIÓN INTERIOR, Ley de 30 de agosto de 1907 y Reglamento para su ejecución de 23 de octubre de 1918, Madrid, 1918, p. 3-8. 


\section{2.- EL PROYECTO DE COLONIZACIÓN}

\section{2a. Aspectos técnicos: área cultivable y tamaño de los lotes}

La Sierra de Salinas situada a caballo de las provincias de Alicante y Murcia, figuraba en la Clasificación General de los Montes Públicos de 1859 como propiedad del Estado y exceptuada de la desamortización ${ }^{5}$. Posteriormente en cumplimiento del Real Decreto de 27 de febrero de 1887 se incluyó el Monte en la relación de predios enajenables. Más tarde, en virtud de la Ley de 30 de agosto de 1907, y previo Real Decreto de la Presidencia del Consejo de Ministros de 10 de enero de 1910, la Junta Central de Colonización y Repoblación Interior se hizo cargo de la Sierra al estimarla colonizable y llevó a cabo dos establecimientos coloniales, uno en cada provincia, llamados: «Sierra de Salinas» el de Villena, y «Coto de Salinas» el de Yecla.

El proyecto de colonización de Sierra de Salinas realizado por el ingeniero agrónomo Luis Beneyto, abarca una superficie de $1.363 \mathrm{Ha}$ de monte ${ }^{6}$, de las que casi dos tercios se consideran con posibilidades agrícolas -852 Ha-, con utilidad forestal el 35,9\% -489 Ha-, y tan sólo el 1,6\% de la superficie colonizable, formada por roca madre, se consideró inculta. En la superficie productiva el autor del proyecto estableció diversos aprovechamientos según la naturaleza del terreno, compaginando los agrícolas con los forestales (vid. cuadro II).

La zona a colonizar por los cultivos se parceló en 49 lotes a repartir entre los colonos, la superficie asignada a cada uno estuvo en relación con la calidad del suelo. La extensión de los lotes quedaba comprendida entre 7,56 y $20,43 \mathrm{Ha}^{7}$, con predominio de las suertes de mayor tamaño pues, el 55,1 \% de los lotes era superior a las $20 \mathrm{Ha}$ (vid. cuadro III).

\section{2b. Aspectos humanos: los colonos y sus viviendas}

Una vez amojonados los 49 lotes de tierras, se celebró el 21 de abril de 1914 en la Casa Consistorial de Villena ante el alcalde y el delegado de la Junta Central de Colonización, como presidente del Consejo de Administración de

5 MINISTERIO DE FOMENTO, Clasificación general de los montes públicos. Aprobada por Real Orden de 30 de septiembre de 1859, Madrid, 1859, Provincia de Alicante, p. 3.

6 Archivo del I.R.Y.D.A. de Alicante, en adelante A.I.A., Carpeta Sierra de Salinas. Copia del Informe de los señores vocales don Pedro de Ávila y don Ernesto de la Loma sobre el proyecto de colonización del monte «Sierra de Salinas» enclavado en el término municipal de Villena, provincia de Alicante, redactado por el ingeniero agrónomo don Luis G. Beneyto, bajo la dirección de don Enrique Alcaraz, documento XVIII - 10, año 1909, p. 5.

7 COLONIZACIÓN Y REPOBLACIÓN INTERIOR, «Colonia Sierra de Salinas», Boletín de la Junta Central, n. ${ }^{\circ}$ 2, Madrid, 1919, p. 27. 
la Cooperativa que se iba a poner en marcha, el sorteo de los lotes entre los 49 colonos que previamente habían sido seleccionados ${ }^{8}$.

Dos meses después, el 24 de junio, se tuvo qué proceder a un nuevo sorteo para cubrir las vacantes que dejaron 15 personas. Dos renunciaron alegando motivos de salud, y los restantes no tomaron posesión el día de la constitución de la cooperativa. Como causa del abandono se señaló el no «convenirles hoy el lote» ${ }^{9}$. Esto hizo posible que algunos de los primeros adjudicatarios permutaran su lote antes de proceder al nuevo sorteo. Renuncias y cambios de tierras motivados por las dificultades que los colonos veían para la puesta en cultivo y por la desconfianza en la productividad de sus lotes.

\section{CUADRO II}

Tamaño de los lotes y superficie de los mismos en la colonia Sierra de Salinas.

\begin{tabular}{|c|c|c|c|c|}
\hline Tamaño (Ha.) & N. ${ }^{o}$ Lotes & $\%$ & Superficie (Ha.) & $\%$ \\
\hline$<$ de 10 & 2 & 4,08 & 16 & 1,88 \\
\hline $10-14,99$ & 12 & 24,49 & 135 & 15,84 \\
\hline $15-19,99$ & 8 & 16,33 & 146 & 17,14 \\
\hline \multirow[t]{2}{*}{$>$ de 20} & 27 & 55,10 & 555 & 65,14 \\
\hline & 49 & 100 & 852 & 100 \\
\hline
\end{tabular}

\section{CUADRO III}

Clasificación de terrenos en la colonia Sierra de Salinas (Aprovechamiento)

\begin{tabular}{|c|c|c|c|c|c|c|}
\hline Superficie & Extensión (Ha.) & $\%$ & $\underline{\text { Sin pinos }}$ & $\%$ & Con pinos & $\%$ \\
\hline Cultivable & 852 & 62,5 & 616 & 73,9 & 236 & 45,8 \\
\hline Forestal & 489 & 35,9 & 218 & 26,1 & 271 & 54,2 \\
\hline \multirow[t]{2}{*}{ Improductiva } & 22 & 1,6 & - & - & - & - \\
\hline & 1.363 & 100 & 834 & 100 & 515 & 100 \\
\hline
\end{tabular}

La selección de los colonos no resultó tarea fácil. Todos los peticionarios tenían la misma extracción social, aspecto éste que se sobrevaloraba a la hora 1, año 1914.

8 A.I.A., Carpeta Sierra de Salinas, Expediente de concurso de adjudicación de lotes, documento XVI -

9 A.I.A., Carpeta Sierra de Salinas, Expediente sobre diferentes renuncias y adjudicaciones, documento XVI - 2, año 1914. 


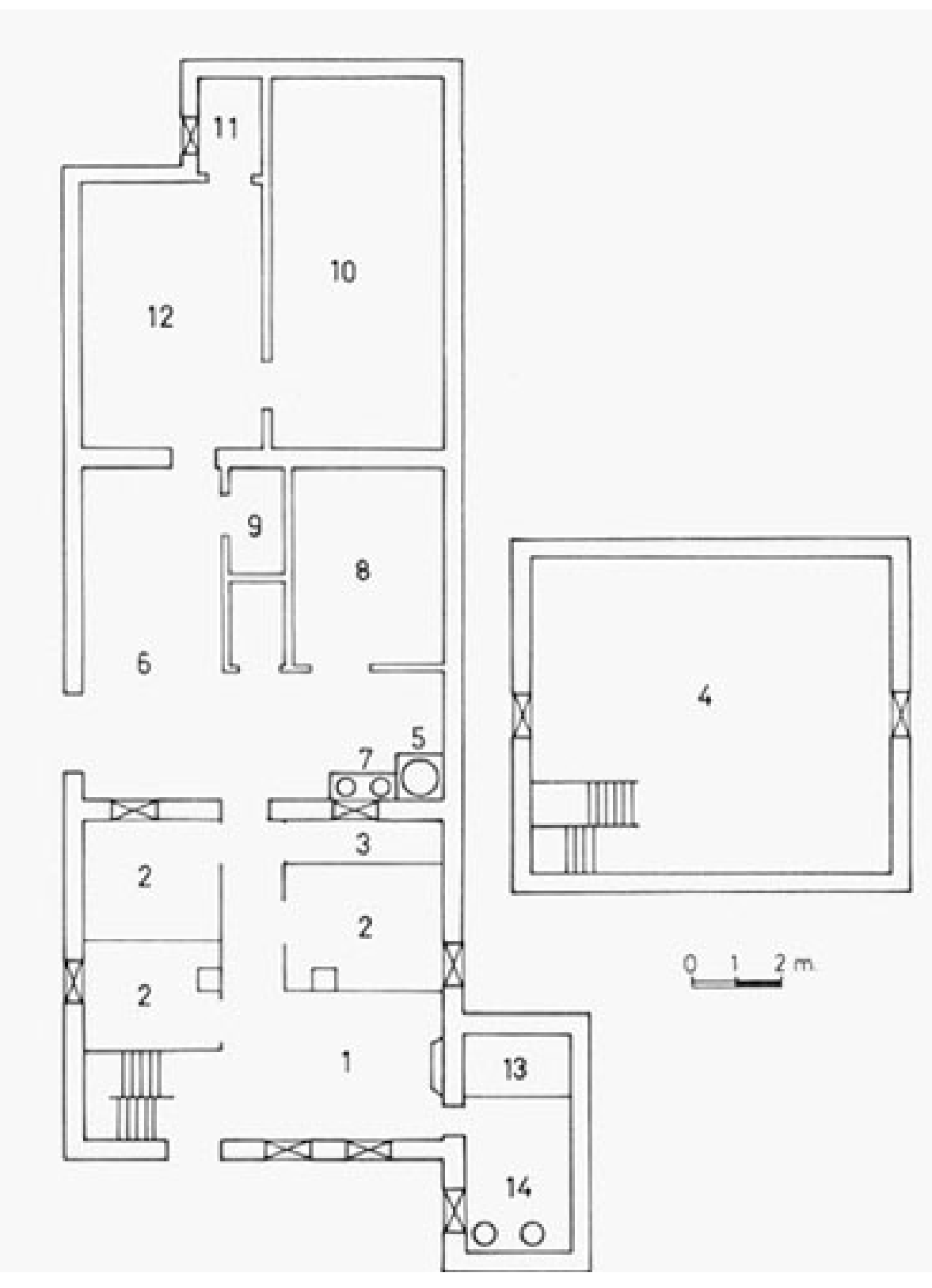

FIGURA 1. Planta de vivienda de colono en Sierra de Salinas; 1, cocina; 2, dormitorio; 3, despensa; 4, almacén, 5 , pozo; 6, sitio para el carro, 7, fregadero; 8, cochiquera; 9, gallinero; 10, cuadra; 11, retrete; 12, estercolero. El plano refleja asimismo el añadido posterior de una habitación en el lateral derecho de la casa y con el acceso desde la cocina donde se ubica el horno (13) y otro fregadero (14). 
de conceder el lote. En todas las solicitudes se lee «jornalero agrícola pobre absolutamente», de ahí que se tuvieran que valorar otros parámetros en la selección, a la que sólo podían aspirar por Ley, los casados, viudas o viudos, con hijos, dándose preferencia a los del término municipal en el que estaba instalada la colonia. En igualdad de circunstancias se optaba por los que tuvieran mayor número de hijos en condiciones para las labores del campo.

El censo de población de la colonia en 1923 era de 287 habitantes. Los 49 cabezas de familia, adjudicatarios de los lotes, procedían casi en su totalidad de Villena, municipio en que estaba enclavada la colonia, con 38 colonos (el 77,6\%), y los restantes de municipios próximos: tres colonos de Yecla, dos de Cañada y uno de Campo de Mirra, Petrel, Penáguila, Alcoy, Caudete y Mogente ${ }^{10}$.

La colonia constituía un pequeño núcleo de población rural, formado por los edificios comunales, agrupados en la parte central del área colonizable y por las viviendas de los colonos, situadas cada una en su lote, si bien se procuró la mayor proximidad de las mismas.

La vivienda del colono se compone de dos plantas: la baja está compuesta por un pequeño vestíbulo, que a un lado tiene la escalera, y al otro, la entrada de la cocina. De la cocina arranca un pasillo -que da acceso por el interior de la vivienda a la cuadra- con dos puertas a cada lado: la primera de la derecha da a un dormitorio, y la segunda a la despensa; las de la izquierda dan entrada a otros dos dormitorios el último de ellos con ventana al corral para desde él dominar por la noche la puerta de la cuadra.

La planta alta de la vivienda, destinada a granero y almacén, forma un solo compartimento, dividido por tabiques de escasa altura en varios departamentos. Adosada a la casa y con acceso también desde el exterior se encuentra el corral que cuenta con dos dependencias, ambas con cobertizo y parte descubierta. La más próxima a la vivienda contiene el brocal del pozo, fregadero, sitio para el carro, cochiquera y gallinero; en la otra se ubica la cuadra, el estercolero y el retrete.

Una carretera central dividía la colonia. En ella convergían los caminos de servicio de los lotes de tierra, y unía con otra que enlazaba directamente con Villena. En dicho eje central se construyeron los edificios comunales (Iglesia, escuela, almacén, etc.) y las viviendas correspondientes para el Capellán, maestro y guarda que habitaban permanentemente en el lugar. La asistencia médica se realizaba por un facultativo que periódicamente se desplazaba desde Villena. Se agrupaban así los más elementales servicios públicos.

\section{2c. Aspectos agronómicos.}

El plan de cultivos preveía la puesta de cereales, al menos los primeros

10 A.I.A., Carpeta Sierra de Salinas, Censo de población de Sierra de Salinas, documento XVI-7, año 1923. 
años, cultivo que además de admitirlo el terreno lo «exigía imperiosamente» el régimen colonial para la futura alimentación de los $\operatorname{colonos}^{11}$, con el que alternarían otras cosechas complementarias como las leguminosas y los tubérculos en el aprovechamiento del suelo. Paralelamente a la plantación de cultivos herbáceos, el colono tendría que ir plantando progresivamente vid y olivo, cultivos arbóreos que se adaptaban favorablemente a las condiciones topográficas y climáticas del lugar, como se había observado en los terrenos circundantes.

El almendro se desechó al conocerse el régimen térmico, pues para fructificar es necesario que la temperatura no baje de los cero grados centígrados y en la Sierra de Salinas llegaba en ocasiones a los 3 y 4 grados bajo cero en los meses de febrero y marzo, época de la florescencia y fructificación, además de comprobarse su escasa rentabilidad en fincas vecinas (casa del Puerto).

Una vez realizadas las operaciones topográficas y la adjudicación de los lotes, comenzarían las obras comunales y las particulares. El Estado anticipó el auxilio metálico que la Ley autorizaba, cuyo objeto era la compensación de los muchos jornales que se han de consumir en levantar la piedra del lote, formar con ella ribazos, transportar la sobrante a los linderos, nivelar en lo posible algunas piezas del terreno y por último efectuar las labores preparatorias, operaciones estimadas como costosísimas y en la que toda una familia (como mínimo tres personas) consumía al menos 30 días de trabajo por $\mathrm{Ha}^{12}$.

Es de destacar que en una valoración realizada en 1908 sobre los futuros territorios agrícolas de la colonia se puso de manifiesto que la superficie era excesivamente accidentada y que en sus laderas había suelo suficiente para que se implantaran toda clase de cultivos, con la sola condición de contener la tierra y las aguas de lluvia con muros de mampostería (ribazos), muros que permiten transformar las laderas inclinadas en bancales propios ya para el cultivo. Práctica, que de no haberse generalizado su uso en la agricultura local, en terrenos próximos a la colonia, no hubiesen permitido considerar las tierras de la Sierra de Salinas como aptas para el cultivo. Asimismo señalaba que las cuidadas plantaciones de vides y olivos que hay en sus laderas «muchas de ellas en terrenos tomados al monte arbitrariamente ${ }^{13}$, eran prueba de lo cultivable y fértil que era la tierra de esta Sierra.

Para evitar un endeudamiento mayor por parte de los colonos, dado el alto precio que hubieran tenido que pagar por la adquisición de los pies de olivo, se creó un vivero por cuenta de la colonia en unas tahúllas de regadío, que Op. cit, p. 6.

11 A.I.A., Carpeta Sierra de Salinas, Copia del informe de los señores vocales don Pedro de Ávila y ...,

12 A.I.A, Carpeta Sierra de Salinas, Copia del informe de los señores vocales don Pedro de Ávila y ..., Op. cit, p. 15.

13 A.I.A., Carpeta Sierra de salinas, Informe sobre las condiciones que para el cultivo agrario ofrece el monte enajenable del Estado denominado Sierra de Salinas en el término municipal de Villena, provincia de Alicante, documento n. ${ }^{\circ}$ 30, año 1908. 
se tomaron en arrendamiento en la vega de Villena, próximos a la colonia ${ }^{14}$, vivero que en cinco años tenía que suministrar los pies necesarios para la plantación. En este período de tiempo, se pensaba recoger abundantes cosechas de cereal, pero se temía un agotamiento de la fertilidad superficial, y al tenerla que buscar en las capas más profundas ningún cultivo era más idóneo que la vid y el olivar. De manera que las plantaciones se irían ejecutando poco a poco, conforme se fuera roturando el terreno y al mismo tiempo que se plantaran vides se harían las del olivar, asociado en un primer momento con la vid, ante la posible extinción de la misma por agotamiento natural o por invasión filoxérica. Con ello se aseguraba un rendimiento mayor para el porvenir.

\section{3.- RESULTADO DE LA COLONIZACIÓN}

La evolución de la colonia Sierra de Salinas queda reflejada en los acuerdos que la Junta local de Colonización remetía a la Junta Central.

En el proyecto de colonización y en todas las valoraciones que se realizaron antes de acometerse las obras de infraestructura se señalaban, como ha quedado expuesto, el alto desarrollo que alcanzaría la agricultura en este sector. Sin embargo, desde el primer momento, la colonización comienza con mal pie y deja entrever una difícil y dura trayectoria, que se pondría de manifiesto inmediatamente después de realizarse el sorteo de los lotes de tierra entre los colonos.

Las primeras labores consistían en la limpieza del terreno y, como consecuencia, se produjo el arranque de pinos y las críticas correspondientes por parte de los vecinos del municipio ante la pérdida de riqueza foresta ${ }^{15}$. Los colonos se dieron con ahínco a la roturación de su lote, emprendiendo el laboreo de sus tierras con la siembra de cereal, pues era preciso asegurar ante todo la vida económica en los primeros años de colonización, lo cual no hubiera sido factible dedicando las primeras roturaciones a plantaciones de olivo y viña, cultivos no rentables de forma inmediata. Pese a las abundantes cosechas que se recogieron en los primeros cuatro años, al aprovechar la capacidad productiva de unos suelos vírgenes, la producción de cereal no llegó a cubrir las necesidades de cada familia, de manera que algunos colonos renunciaron a sus lotes (nueva muestra de las dificultades a las que se enfrentaban).

14 COLONIZACIÓN Y REPOBLACIÓN INTERIOR, «Colonia Sierra de Salinas», Boletín ...Op. cit., p. 30.

15 El Ayuntamiento de Villena el 8 de diciembre de 1911 se oponía al proyecto de Colonización y solicitaba de Ministerio de Fomento el abandono del mismo, por la pérdida de riqueza forestal, así como por los perjuicios que la erosión ocasionaría en las tierras cultivadas limítrofes. El Ministerio de Fomento en fecha 2 de agosto de 1912 desestimó dicha solicitud, por considerar que la obra colonizadora además de mejorar el monte en su aspecto puramente forestal, contribuía a contener los arrastres de tierra con los ribazos de piedra y la posterior plantación de vides y olivos. Archivo Municipal de Villena, actas municipales de las fechas indicadas, cortesía de M. Teresa Villar Mira, encargada del archivo. 
En enero de 1921 el Presidente de la Cooperativa hacía balance de los años transcurridos desde la fundación de la colonia, consideraba que si las primeras cosechas levantaron el ánimo de los colonos, pronto se perdió ese entusiasmo inicial, debido a la adversa naturaleza del terreno y a las condiciones climáticas (sequías en el momento de la siembra, heladas tardías...); peor fue la desgana de los propios labradores: «os habéis acostumbrado a tener asegurado en el almacén el pan de cada día con poco trabajo y no queréis enteraos que es a vosotros, y no a la Junta Central a quien corresponde la obligación de aprovisionar de nuevo ese almacén» ${ }^{16}$.

El desaliento había cundido y las labores agrícolas se realizaban perezosamente, con lo que el desenvolvimiento de la colonia se había retrasado. Sirva como prueba el hecho de que en 1918 la superficie roturada - 151 Ha- equivalía sólo al 18\% del total cultivable ( $852 \mathrm{Ha}$ ); al año siguiente la extensión cultivada se incrementó con 64 Ha más, y en 1920 con 35 nuevas hectáreas. El descenso de la producción de cereal, pese a contar con un mayor número de hectáreas roturadas y el acuerdo tomado por el Consejo de la Colonia de empezar a plantar viñedo, del que se desconocía si prendería bien en los terrenos, hizo que las roturaciones se resintieran. Según palabras del Presidente de la Cooperativa cuando se les exigía a los colonos un «esfuerzo pequeño» éstos respondían por regla general con «escasa voluntad y mala gana» ${ }^{17}$ (vid. cuadro IV).

\section{CUADRO IV}

\begin{tabular}{|c|c|c|c|}
\hline \multirow[b]{2}{*}{$A \tilde{n} o$} & \multicolumn{3}{|c|}{ Sierra de Salinas: producción de cereal y superficie roturada } \\
\hline & $\begin{array}{c}\text { Producción cereales } \\
K g .\end{array}$ & $\begin{array}{l}\text { Ha. roturadas hasta } \\
31 \text { de diciembre }\end{array}$ & $\begin{array}{l}\% \text { sobre total } \\
\text { cultivable }\end{array}$ \\
\hline 1918 & 111.990 & 151 & 18 \\
\hline 1919 & 85.907 & 215 & 25 \\
\hline 1920 & 109.6090 & 250 & 29 \\
\hline
\end{tabular}

La demora en el plan de roturación llevó consigo la del acceso por los colonos a la propiedad de la tierra. Estaba previsto que la adquisición de la tierra se produjese a los cinco años, pero no sería hasta finales de los años veinte, es decir, transcurridos más de diez años, cuando se termina de crear el nuevo espacio agrícola en el monte. Este largo período de tutela por parte de la Administración no estuvo exento de problemas (reuniones antirreglamentarias, intentos de independencia de los colonos de la Cooperativa para vender perso-

16 COLONIZACIÓN Y REPOBLACIÓN INTERIOR, «Memoria de la Asociación Cooperativa de colonos de la colonia agrícola de Sierra de Salinas, correspondiente al año 1920», Boletín de la Junta Central, n. ${ }^{\circ}$ 10, Madrid 1921, p. 23.

17 COLONIZACIÓN Y REPOBLACIÓN INTERIOR, Op. cit., p. 23. 
nalmente las cosechas, etc. $)^{18}$. La escasa rentabilidad de las producciones obtenidas vino a agravar la situación anterior, pues los colonos recurrían a continuos créditos que tendrían que saldar para acceder al dominio directo de la tierra.

En octubre de 1927 el director de la colonia solicitaba que la Junta Central remitiera los títulos de propiedad de cuatro lotes al no tener sus colonos deudas contraídas con el Estado y estar dispuestos a saldar la que tenían con la Cooperativa, medida que serviría de estímulo a los demás colonos: «con ello se estimulará al resto de los colonos y puede sacarse algún partido de este particular, toda vez que todos están deseando obren en su poder los títulos de propiedad y se me ha ofrecido por bastantes abonar el total de su deuda con el Estado si ello fuera inconveniente para que se les entreguen los dichos títulos».

La Dirección General estimó improcedente la entrega parcial de los títulos por entender que sería origen, más que estímulo, de numerosas desavenencias, y porque tenía encargado la confección de un proyecto de liquidación que comprendería datos relativos al estado de los lotes, cultivos permanentes, deudas por todo concepto de cada adjudicatario, etc. El citado proyecto estudiaba la entrega de títulos para la generalidad de la colonia «si sus deudas y conducta lo permitieran así; y considerando también que es preciso resolver de modo definitivo y rápido la concesión de la propiedad, diferida durante catorce años de posesión» ${ }^{19} \ldots$

No obstante, el acceso a la propiedad del lote todavía se demoraría varios decenios más, hasta su total liquidación en los primeros años de la década de los cincuenta. Años en los que a pesar de contar con la plena producción de los cultivos arbóreos, en muy poco mejoró las condiciones de vida en la colonia, por lo que resultaba difícil saldar la deuda contraída cuando las cosechas apenas daban para sobrevivir. El acta de la Junta de Colonización de 1932 ponía de manifiesto que «los colonos no pueden vivir con los productos obtenidos de sus lotes... con lo que es imposible que puedan atender al mantenimiento de sus familias $»^{20}$, por lo que solicitaban moratoria en el pago de los intereses que tenían que satisfacer a la Cooperativa.

Afirmaciones como la citada son una constante en el desarrollo de la colonia. Para atajar estos males se adoptaron medidas consistentes en autorizar la tala de pinos, no sólo los del lote sino también los de la zona comunal, bastante aclarado ya por anteriores e «intensas cortas», a fin de dar trabajo a los colonos y para aportar ingresos a la Cooperativa a la que realmente pertene-

18 A.I.A., Carpeta Sierra de Salinas, Expediente sobre intento de reunión antirreglamentaria por los colonos, documento XVI-6, año 1923. XVI-13, año 1927.

19 A.I.A., Carpeta Sierra de Salinas, Expediente sobre entrega de varios títulos de propiedad, documento

20 A.I.A., Carpeta Sierra de Salinas, Acta 8 de mayo de 1932 e informe posterior de la Asociación Cooperativa de colonos de Sierra de Salinas, documento XXXIII-45. 
cían estos aprovechamientos, entidad encargada de la venta y que con los fondos recaudados concedía ayudas a los más necesitados por los gastos de la poda y acarreo de la leña ${ }^{21}$.

En el informe que en 1934 elaboró un ingeniero agrónomo mandado por el Instituto de Reforma Agraria se lee que algunos lotes estaban completamente abandonados - «sin vestigios de cultivo»- desde hacía más de dos años y otros desde casi un decenio, tiempo éste en el que el monte había invadido el viñedo y el olivar. Dicho informe solicitaba con urgencia para estas parcelas las oportunas labores agrícolas, pues de lo contrario se perderían los cultivos plantados. Para ello proponía dos soluciones, una vez realizados los correspondientes expedientes de expulsión de los colonos responsables: sacar de nuevo a concurso los lotes de tierra entre los jornaleros pobres de Villena o entre los familiares de los colonos actuales, o bien que, sin vulnerar el espíritu de indivisibilidad que los lotes tenían en la Ley, se pudieran dividir temporalmente entre los colonos reconocidos como buenos labradores.

Se optó por la última solución, no sólo por ser la más rápida para no tener por más tiempo improductivos los terrenos, sino porque la primera resultaba poco atractiva, dado que por su abandono las tierras requerían muchos jornales. E interesaba que se hiciesen cargo de la deuda que cada uno de los lotes tenía contraída con la Cooperativa, aunque el Crédito Agrícola concediese anticipos para su amortización; la medida adoptada, si bien no eliminaba este gravamen, lo dividía proporcionalmente a la superficie concedida a cada colono y no implicaba ningún desembolso por parte del Instituto. Una vez mejorados estos lotes, y sin cargas, se sacarían a concurso en circunstancias más favorables ${ }^{22}$.

Por tanto, la evolución de la colonización estuvo plagada de problemas y obstáculos, que acarrearon que el proyecto se realizase con un notable retraso e incluso con abandono de diversos colonos, no dispuestos a soportar las duras condiciones en las que tenían que desenvolverse.

\section{4.- LIQUIDACIÓN DE LA COLONIA}

El acceso de los colonos a la propiedad de la tierra no se realizaría en los cinco años que el Proyecto General de Colonización tenía fijado, pues los problemas que surgieron (malas cosechas y las peticiones reiteradas de crédito) demoraron la adquisición del dominio directo, ya que para conseguirlo había que amortizar la deuda contraída con la Cooperativa.

21 A.I.A., Carpeta Sierra de Salinas, Acta 15 de octubre de 1932 e informe posterior de la Asociación Cooperativa de colonos Sierra de Salinas, documento XXXIII-53.

22 A.I.A., Carpeta Sierra de Salinas, Expediente sobre deficiencias en el cultivo de algunos lotes en la colonia Sierra de Salinas, documento XIV-28, año 1934. 
La Asociación Cooperativa era el organismo de administración y gobierno de la colonia, atendía todas las necesidades de los colonos, por pequeñas que éstas fueran, cuidaba de que en el almacén de consumo nunca faltasen los artículos, no solamente necesarios, sino también superfluos; se hacía cargo de los productos recolectados en las distintas parcelas; disponía los trabajos y prestaciones personales así como los aprovechamientos comunales que tenían que hacerse y todo esto, mediante vales de producción y consumo que, cargados en las libretas de los colonos, engrosaban su crédito o acrecentaban su deuda.

Las libretas de cuentas eran por consiguiente un fiel reflejo de la laboriosidad o negligencia de los colonos, pero su utilización resultó poco efectiva y fue sustituida por unos créditos que, a primeros de año, en forma de cupones representativos de papel moneda se entregaban a cada colono para que se dieran cuenta de que con su crédito tenían que cubrir los gastos del año, sin poder excederse del total estipulado; pero la práctica demostró que tampoco este tipo de control resultaba efectivo pues los créditos asignados, se gastaban muchas veces antes de que finalizase el año, teniendo que recurrir a ampliaciones del mismo. En 1920 el presidente de la Asociación Cooperativa señalaba «que el crédito desaparecía en unos cuantos meses confiando para el porvenir en los buenos corazones de los vocales del consejo y en las ubres de la Cooperativa, que ya tenéis exhaustas y agotadas...» ${ }^{23}$, y proponía que, en adelante, y para dar una solución a la mala administración de los colonos, sólo se podría invertir en el almacén mensualmente la parte proporcional del crédito asignado a cada uno, parte que se establecería teniendo en cuenta su deuda con la Cooperativa.

Difícil resultaba aplicar estas medidas restrictivas en momentos de desastre económico para la colonia y en los que el almacén era el único establecimiento capaz de proporcionar los alimentos necesarios para la subsistencia, como puso de manifiesto el secretario del Consejo de Administración de la Cooperativa el 16 de julio de 1933 a raíz de varios años consecutivos de ruinosas cosechas: «se acuerda exponer a la Superioridad, el lamentable estado en que se hallan hoy los colonos, al ver (...) como son ya tres malas cosechas, una por helada; la del año pasado por pedrisco, y ésta por el mildiu, no saben qué camino tomar, por ser todos acreedores los que les visitan y no pueden pagar a nadie y menos comer porque no les fían en Villena ${ }^{24}{ }$; proponía que, ante la grave situación que atravesaban los colonos, se aplazara la recaudación que el plan de liquidación de la colonia estipulaba.

La dificultad para amortizar las deudas contraídas con la Cooperativa demoraría los planes de liquidación hasta principios de los años cincuenta, en

${ }^{23}$ COLONIZACIÓN Y REPOBLACIÓN INTERIOR, «Memoria de la Asociación Cooperativa de colonos de la.... Op. cit., p. 26.

24 A.I.A., Carpeta Sierra de Salinas, Acta 16 de julio de 1933 de la Asociación Cooperativa de la Colonia Sierra de Salinas, documento XXXIII-62. 
que, por oficio de 28 de enero de 1952, se le comunicó al Ingeniero Jefe del servicio Forestal del Instituto Nacional de Colonización en Alicante que debía efectuar la liquidación de las Colonias Agrícolas que dependían de su Delegación antes del 1 de enero de 1953, encontrándose entre éstas las de Sierra de Salinas y Coto Salinas, previo informe de un ingeniero de montes y otro agrónomo, realizándose estas tareas con carácter urgente para que quedaran resueltas dentro del plazo fijado.

La propuesta de liquidación de la colonia Sierra de Salinas determinaba: que se condenara el saldo deudor de 37.274 ptas. que arrojaba la citada colonia; que la zona comunal, poblada de pinos jóvenes y en explotación forestal, junto con los lotes abandonados y los edificios comunales (almacén, escuela, Iglesia, etc.) con sus zonas anejas, pasaran al Estado a través de la Dirección General del Patrimonio Forestal; y que se adjudicarán a los actuales colonos cultivadores de los 46 lotes restantes la propiedad de los mismos, haciendo entrega de los títulos correspondientes, en los que se haga constar que éstos están totalmente liquidados ${ }^{25}$. De esta forma terminaba el largo y penoso camino de la adjudicación de las tierras a los colonos, objetivo fundamental en toda la colonización.

\section{CONCLUSIÓN}

La evolución de la colonia agrícola Sierra de Salinas y los resultados conseguidos distan mucho de las aspiraciones que la Ley marcó en su día. Los colonos, tras largos años de tutela de Estado, han logrado la propiedad de la tierra, pero no era éste el único fin de la legislación de 1907, que inspirada en el prejuicio, muy en boga por aquellas fechas, de que la inferioridad de nuestra producción agraria se debía en gran parte a las inmensas extensiones de terrenos incultos, intentaba con sus disposiciones la creación de nuevos espacios agrícolas.

Desde los inicios de la colonia Sierra de Salinas, se pusieron de manifiesto serios problemas que hacían vislumbrar el fracaso de la colonización; al abandono de colonos y a la poca rentabilidad de las cosechas hay que añadir entre

25 A.I.A., Propuesta para la liquidación de la colonia Sierra de Salinas, ingeniero de montes don Augusto González Regueral. Alicante, 1952, documento n. ${ }^{\circ} 40$.

A diferencia de la colonia Sierra de Salinas, la establecida también en dicho monte y denominada «Coto de Salinas», enclavada en el municipio de Yecla, provincia de Murcia, con una superficie de 1.290 Ha de las que sólo se consideraron cultivables $189 \mathrm{Ha}$, repartidas en diez lotes de tierra, arrojaba en el informe de liquidación de 1952 un saldo acreedor de 453.239 pesetas favorable a los colonos, dado los importantes ingresos que producía la zona forestal, con más de mil hectáreas de terreno comunal. En consecuencia se determinó la adjudicación de la propiedad de la tierra a los colonos y se atribuyó el saldo activo de los colonos al Instituto Nacional de Colonización, quien en la práctica llevaba a cabo la explotación del monte. A.I.A., Propuesta para la liquidación de la colonia «Coto de Salinas», ingeniero de montes Augusto González Regueral. Alicante, 1952, documento n. ${ }^{\circ} 409$. 
otros: la no construcción de la bodega y almazara como estaba proyectado; la insuficiencia de los lotes, que hizo necesario ampliar algunos a costa de la superficie comunal, sobrepasando el límite máximo que recogía el proyecto de colonización $(20,43 \mathrm{Ha})^{26}$; y el relativo aislamiento de colonia, pese a encontrarse en las inmediaciones de Villena, a menos de $15 \mathrm{Km}$, y contar con una red de comunicación de nueva creación que no siempre se encontraba en perfectas condiciones para el tránsito carretero.

$\mathrm{Al}$ optimismo que reflejan los primeros informes antes de la colonización siguió una revisión más crítica en las últimas valoraciones: «lo accidentado del terreno, lo impropio para el cultivo (...) y la mediana calidad del suelo» ${ }^{27}$ eran las causas que se señalaban en el informe de 1934 sobre el poco éxito alcanzado por la colonización. A estos aspectos hay que añadir la adversidad climática y sobre todo el ambicioso plan de crear un amplio espacio agrícola, aun excediendo con creces la superficie que reunía dicha utilidad, (pues en un informe previo a la roturación, en 1908, se consideraban aptas para la agricultura de 250 a $300 \mathrm{Ha}^{28}$, extensión que con posterioridad, al aprobarse el proyecto de colonización, quedó fijado en $852 \mathrm{Ha}$ ).

La labor colonizadora que emprendió el Estado con la Ley de 1907, no culminó con el éxito previsto, no sólo en la colonia Sierra de Salinas, sino tampoco en los restantes grupos coloniales del país, pues como apunta Enrique Alcaraz, la referida normativa tuvo por objeto de colonización los montes públicos que estaban en poder del Estado desde la desamortización, y que al no considerarse apropiados para la instauración o restauración forestal, fueron confiados al Ministerio de Hacienda para su administración y posterior venta, de manera que aquéllos que reunían aptitud para el cultivo o pasto fueron los primeros en pasar a propiedad privada, y al publicarse la Ley de Colonización y Repoblación Interior «sólo quedaban en poder de dicho Ministerio, los que nadie había querido todavía, y aun éstos, notablemente mermados en su parte cultivable por las llamadas roturaciones arbitrarias». Por todo ello Alcaraz se-

26 En el cultivo de los lotes, la práctica demostró la insuficiencia de algunas superficies, dada la mala calidad del terreno siendo necesario ampliar los lotes a costa de rodales de pino de aprovechamiento comunal que existían en sus lindes. En las ampliaciones tuvieron preferencia los titulares que poseían los lotes de tierra de más deficiente producción, por lo general los que disfrutaban las suertes de mayor tamaño, sin que en ningún caso se superara las $30 \mathrm{Ha}$. En el informe de liquidación de la colonia de 1952, la superficie cultivada era superior en 37 Ha a la que establecía el Proyecto de Colonización -889 Ha y 852 Ha respectivamente- fruto de las sucesivas roturaciones en la zona forestal, que alteraron el tamaño inicial de los lotes.

27 A.I.A., Carpeta Sierra de Salinas, Expediente sobre deficiencias en el cultivo de algunos lotes en la colonia de Sierra de Salinas, documento XIV-28, año 1934.

28 A.I.A., Carpeta Sierra de Salinas. Informe sobre las condiciones que para el cultivo agrario ofrece el monte... Op. cit., en el citado informe se señala que la extensión del monte era de $1.429 \mathrm{Ha}$ «y de ellas podrán ser útiles para el cultivo agrario según aforo del que suscribe de 250 a 300 Ha» firmado Enrique Alcaraz, 11 de mayo de 1908. En el Proyecto de Colonización aprobado, la extensión de la colonia se calculaba en 1.362 Ha y la superficie cultivable quedó fijada definitivamente en $852 \mathrm{Ha}$. 
ñalaba en 1931 que la Ley de 1907 «no podía dar de sí otros frutos», pues centró la acción colonizadora en los montes públicos «como si éstos valieran maldita la cosa en plan de colonización para el cultivo agrario» ${ }^{29}$.

29 ALCARAZ, E., Op. cit. pp. 40-44. 


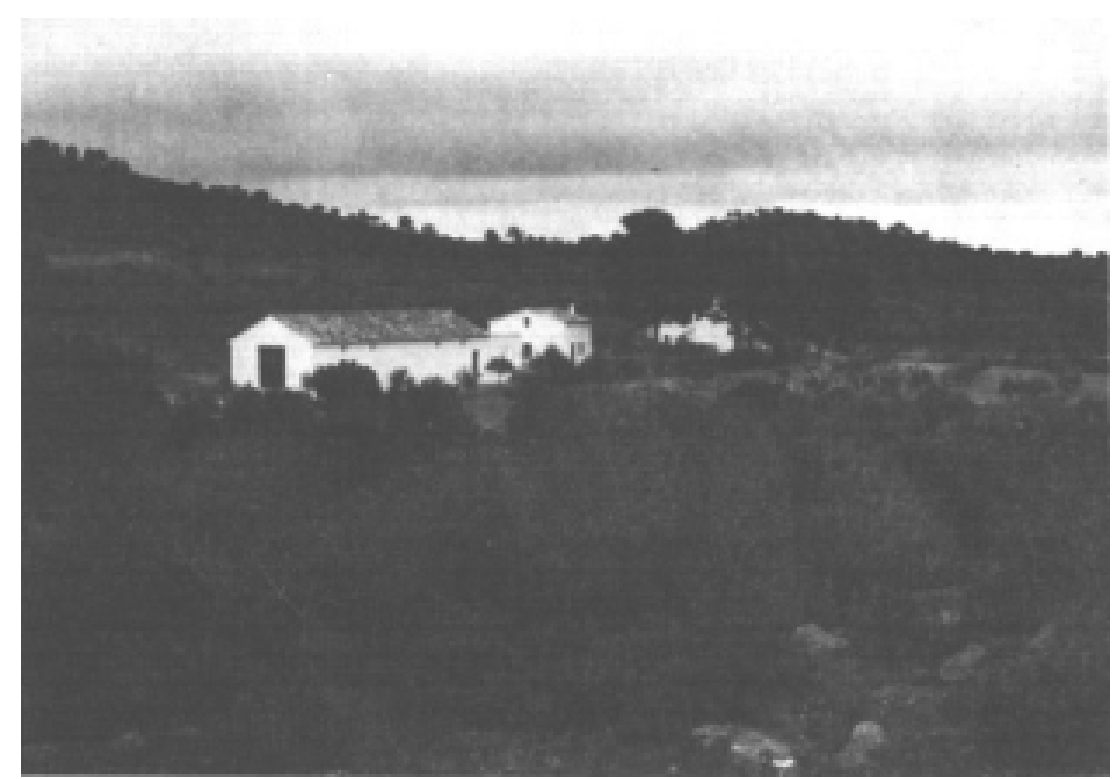

FIGURA 2. Edificios comunales de Sierra de Salinas, en la actualidad sólo se conserva el almacén, la cooperativa y la vivienda del guardia. La iglesia y la escuela han desaparecido, la almazara y la bodega nunca llegaron a edificarse.

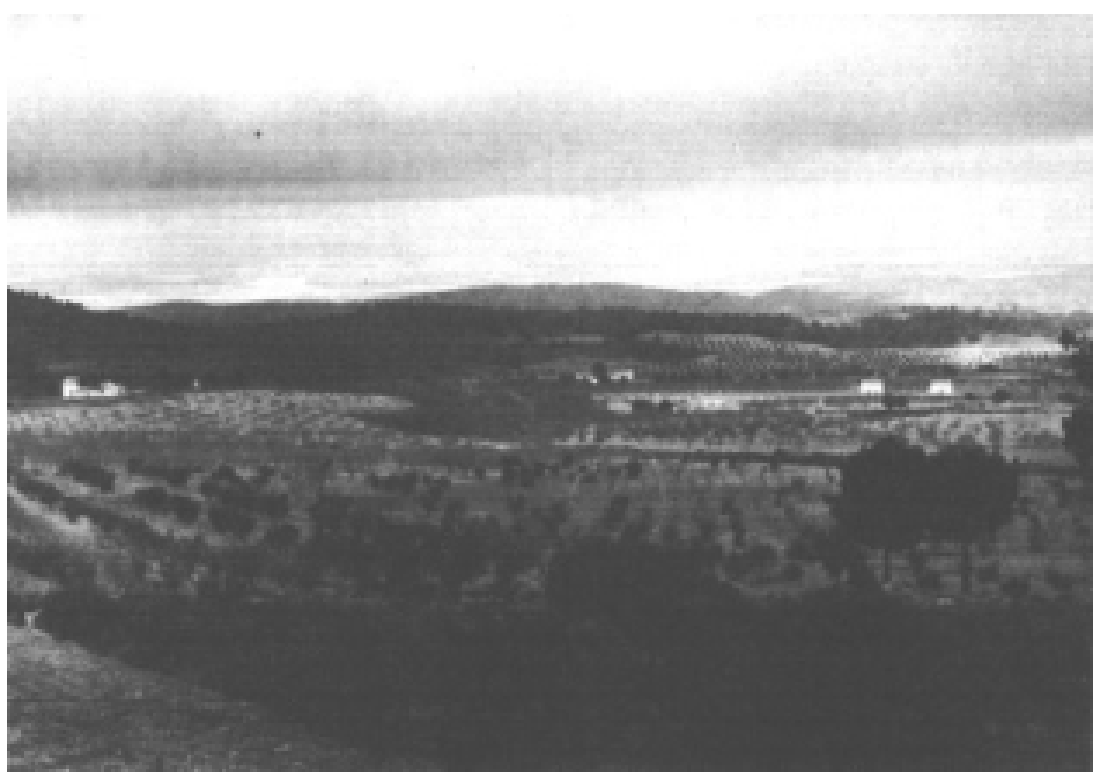

FIGURA 3. Vista parcial de la zona agrícola de Sierra de Salinas, donde todavía son cultivables las suertes con una topografía más favorable. Nótese la dispersión de la población. 


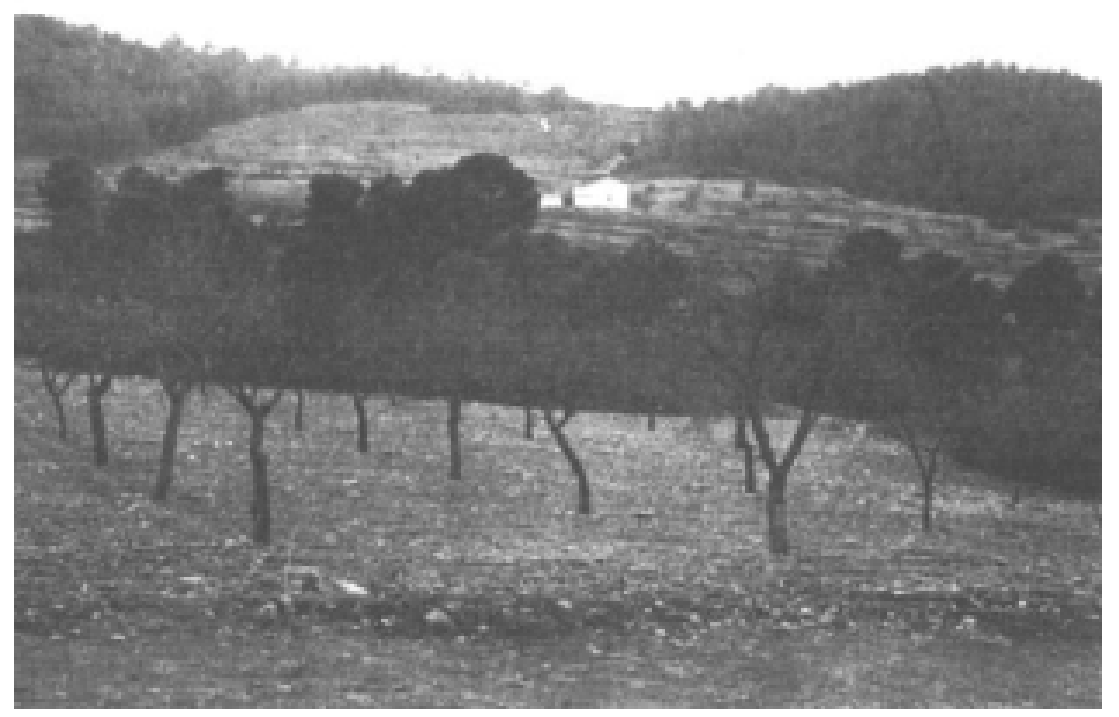

FIGURA 4. Espacio agrario de Sierra de Salinas, que muestra la roturación realizada tanto en las partes allanadas como en la ladera del monte.

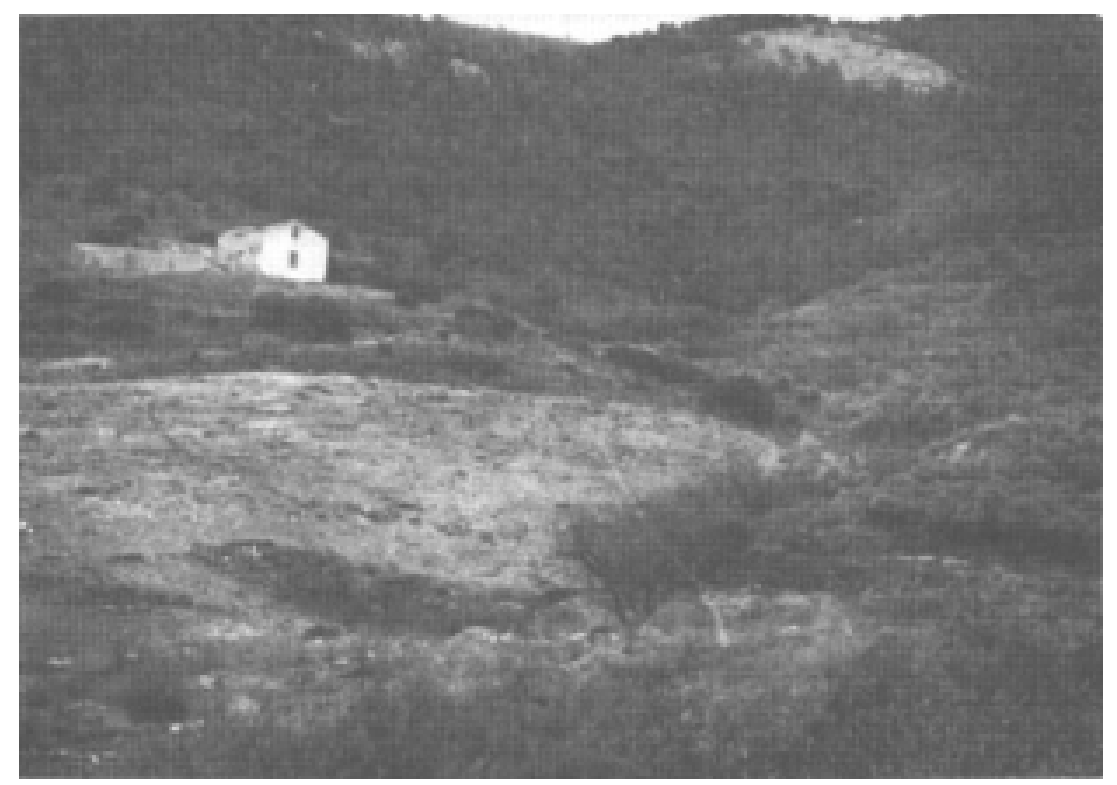

FIGURA 5. Parcela abandonada de la colonia, en la que se aprecia la invasión de la vegetación natural. 